\title{
Use of a novel computerized decision aid for aneuploidy screening: a randomized controlled trial
}

\author{
Laura M. Carlson, MD¹, Sarah Harris, MS², Emily E. Hardisty, MS ${ }^{1}$, Ginger Hocutt, MS ${ }^{1}$, \\ Diane Vargo, MS ${ }^{1}$, Erin Campbell, MS ${ }^{1}$, Elysia Davis, MS ${ }^{1}$, Kelly Gilmore, MS ${ }^{1}$ and Neeta L. Vora, MD ${ }^{1}$
}

Purpose: To assess whether knowledge following use of a decision aid (DA) for aneuploidy screening and testing is inferior to knowledge in women who saw a genetic counselor (GC) only.

Methods: This is a randomized controlled noninferiority trial of pregnant women at $\leq 22$ weeks. Women who were scheduled for GC were randomly allocated to use a DA before GC or to GC alone. The primary outcome was knowledge score, comparing women who had used the DA only to those who saw GC alone. Analysis was by intent to treat.

Results: Between January and October 2017, 197 women were randomized, 105 to GC only and 92 to DA use before GC. Demographics and baseline knowledge were similar between groups. Mean knowledge score following DA use was not inferior to mean knowledge score following GC only (10.4 vs. 10.6, $p=0.306)$. Decisional conflict was similar following completion of the DA to following GC only, but was reduced following completion of both the DA and GC compared with GC only (0.22 vs. $1.74, p=0.003$ ).

Conclusion: Knowledge surrounding aneuploidy screening in women who used a DA was not inferior to knowledge in women who underwent GC. Use of the DA in addition to GC reduced decisional conflict.

Genetics in Medicine (2019) 21:923-929; https://doi.org/10.1038/s41436018-0283-2

Keywords: decision aid; aneuploidy screening; prenatal genetic counseling

\section{INTRODUCTION}

Many different aneuploidy screening and diagnostic testing options are available to patients based on gestational age, all with different risks and benefits. Cell-free DNA screening has improved sensitivity and specificity for common aneuploidies ${ }^{1}$ but likely reduced detection of other chromosomal abnormalities. ${ }^{2}$ However, traditional screenings such as first trimester screening, which have poorer detection characteristics for common aneuploidies, may be more likely to identify pregnancies with other, less common, chromosomal abnormalities. ${ }^{2}$ Diagnostic testing choices include chorionic villus sampling and amniocentesis, both of which carry a low risk of pregnancy loss of approximately 1 in 455 to 1 in 900 respectively. ${ }^{3}$ Counseling on screening and testing options is recommended by the American College of Obstetrics and Gynecology for all women, ideally at the first prenatal visit. ${ }^{4}$ Additionally, recommendations by the American College of Medical Genetics and Genomics (emphasize the importance of appropriate pretest counseling for patients undergoing prenatal screening with cell-free DNA. ${ }^{5}$

This increasing number of screening modalities complicates prenatal counseling for prenatal care providers and can be difficult for patients to understand, especially patients with low health literacy. ${ }^{6}$ While many patients may be aware of trisomy 21, many have never heard of other aneuploidies and may be unfamiliar with the basic principles of genetic screening and prenatal aneuploidy detection.

Because low health literacy affects many women of reproductive age and because most obstetric providers have limited time in an initial prenatal visit to explain the rapidly expanding choice of tests, our aim was to develop a decision aid for aneuploidy screening and testing that could easily be used in various clinics and settings. Decision aids have been shown to improve patients' knowledge and decrease decisional conflict with health-care decisions in health-care settings, ${ }^{6}$ and in the field of obstetrics and gynecology. ${ }^{6,7}$ This is particularly true when decisions are complex and involve patient value assessment. ${ }^{6}$ A decision aid has been previously developed and tested to address aneuploidy screening, ${ }^{8}$ though an important new screening modality in cell-free DNA has become available since the development of this tool. We hypothesize that a computerized decision aid to review available aneuploidy screening and testing options would not be inferior to a counseling visit with a genetic counselor in

${ }^{1}$ Department of Obstetrics and Gynecology, Division of Maternal-Fetal Medicine, University of North Carolina School of Medicine, Chapel Hill, NC, USA; ${ }^{2}$ University of North Carolina School of Medicine, Chapel Hill, NC, USA. Correspondence: Laura M. Carlson (laura_carlson@med.unc.edu) 
increasing patient knowledge. The combination of the decision aid followed by a genetic counseling appointment would also be expected to decrease decisional conflict.

\section{MATERIALS AND METHODS}

A decision aid incorporating all aneuploidy screening and diagnostic testing options available at the time of the study was developed with input from maternal-fetal medicine physicians, a geneticist, and genetic counselors. This was designed within a tablet-based application. The decision aid was also translated into Spanish by a single translator and the translation reviewed by a second native Spanish speaker. The language was simplified to a 10th grade reading level on the Flesch-Kincaid scale. Completion of the decision aid takes approximately $20 \mathrm{~min}$. Information surrounding patient age and gestational age are incorporated to guide the study participant toward available options.

In our health-care system, most women who choose to undergo aneuploidy screening or desire further discussion about screening options after a discussion with their prenatal care provider are scheduled to meet with a genetic counselor prior to screening or testing.

English and Spanish-speaking women with a singleton gestation at less than 22 weeks who were scheduled to meet with a genetic counselor at one of three prenatal diagnosis clinics for a discussion of aneuploidy screening and testing options were eligible for participation. Women with multiple gestations, prior abnormal ultrasound in the current pregnancy, or with prior aneuploidy screening in the current pregnancy were excluded. All women scheduled to meet with a genetic counselor received prior counseling by their prenatal care provider, although the degree of prior counseling likely varied between women and was not discretely documented.

Data collection was embedded within the decision aid, including a demographics survey, knowledge questionnaire, and decisional conflict scale. The previously validated Maternal Serum Screening Knowledge Questionnaire ${ }^{9}$ was modified to incorporate options of cell-free DNA and first trimester screening, resulting in a knowledge questionnaire on a 12-point scale. A previously validated low literacy decisional conflict scale ${ }^{10}$ consisting of ten questions was chosen for assessment of decisional conflict.

An initial pilot study was completed; women meeting eligibility criteria were sequentially contacted and offered participation in the pilot study with a goal enrollment of 20 women. Informed consent was obtained prior to participation. Knowledge was assessed prior to completion of the decision aid. The decision aid was then selfadministered by participants; following completion, knowledge and decisional conflict assessments were repeated. Qualitative feedback was also sought via a structured questionnaire. The decision aid was then updated to reinforce concepts that were frequently answered incorrectly and to incorporate qualitative feedback of pilot participants.

For the randomized trial, charts of women scheduled to see a genetic counselor for a discussion of aneuploidy screening or testing were screened for eligibility and eligible women were contacted within a week before their visit by telephone by trained study personnel. Women who indicated in the medical record that they preferred Spanish were contacted by Spanish-speaking study personnel. Those who agreed to participate were asked to arrive early for their appointment to be enrolled in the study. Informed consent was obtained from all subjects. Following informed consent, the app was accessed and a study ID assigned. Via a coin-flip algorithm within the app, women were randomly assigned to group 1 (control group) or group 2 (decision aid group). As it was not pragmatic for this study, randomization assignment was not blinded. Investigators were not involved in developing the randomization scheme within the app. All women completed an initial demographic and knowledge questionnaire immediately following randomization via self-administered assessments within the app.

Study flow is described in Figure S1. Women randomized to group 1 met with the genetic counselor as scheduled, then completed the knowledge and decisional conflict assessments. Women randomized to group 2 self-administered the decision aid within the app, then completed the knowledge and decisional conflict assessments. Following this, they met with the genetic counselor as scheduled; following this appointment, they again completed the same assessment. Additionally, prior to and following meeting with the genetic counselor, women in group 2 were asked whether they would or did find it helpful to meet with a genetic counselor.

Genetic counselors were educated prior to study initiation that their counseling should not be modified based on group assignment; generally, women $<35$ years old received abbreviated counseling on aneuploidy screening and testing options and those $\geq 35$ years old received more extensive counseling. Within ACMG guidelines, all screening tests were available to all women; cost information and insurance coverage information on available tests were also provided prior to final decision making. Women then underwent their screening or testing modality of choice. All study participation and completion of initial screening were completed within the single encounter. Women who participated received a \$15 gift card incentive for their participation following completion of surveys after genetic counseling.

Following completion of the study, charts of participating women were abstracted to confirm gestational age and demographic information. Choice of testing and results of testing were recorded. All data was abstracted by the primary investigator into the REDCap data management system. ${ }^{11}$ Data entry was double-checked for accuracy.

The primary hypothesis of this study was that knowledge scores of women in group 2 following completion of the decision aid only would not be inferior to knowledge scores of women in group 1 following genetic counseling. A noninferiority limit of 1 question different on a 12-point questionnaire was selected as a clinically relevant difference. An initial power calculation was performed using historical data from the Maternal Serum Screening Questionnaire assuming a 


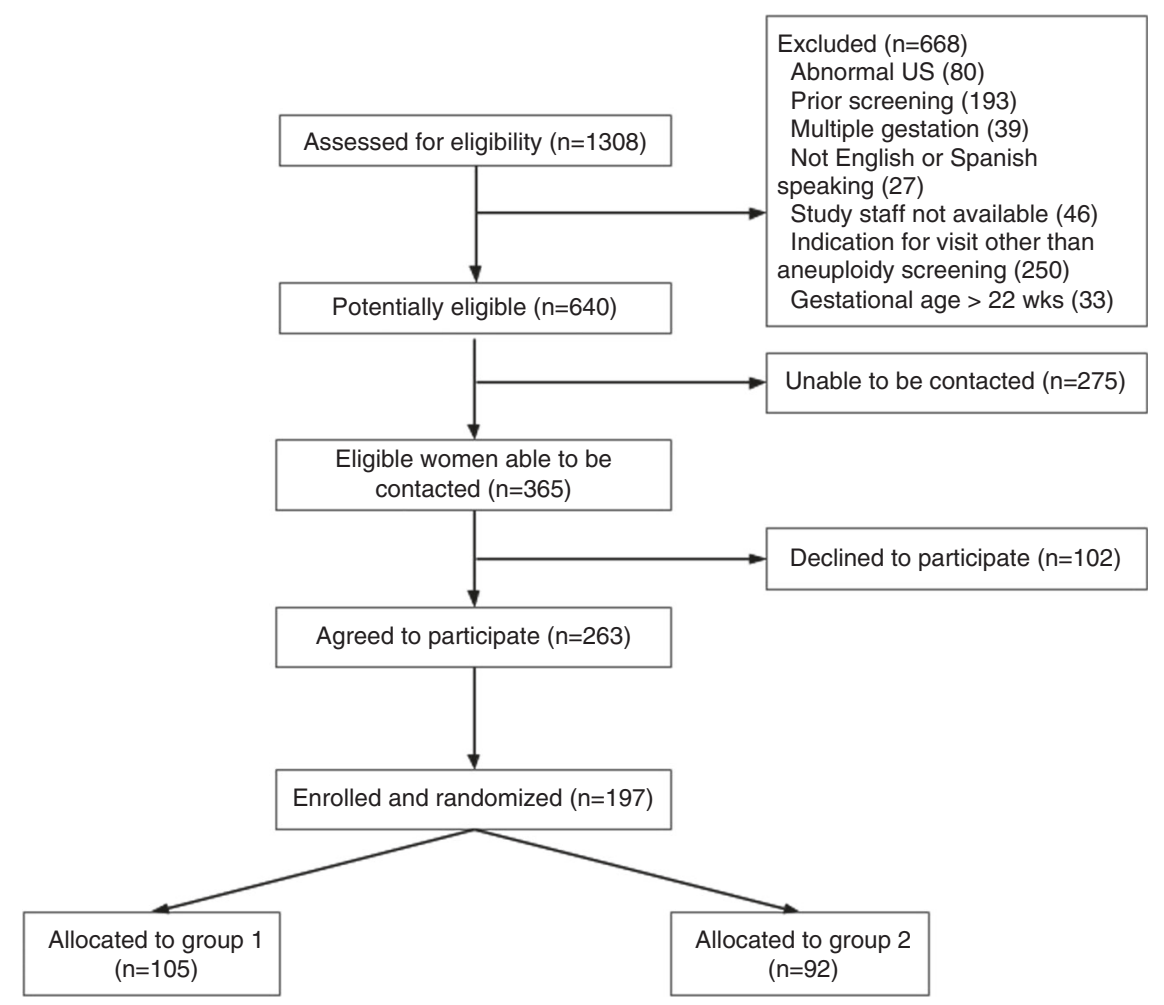

Fig. 1 Participant enrollment. US ultrasound

standard deviation of 3 questions; to achieve $80 \%$ power with a 2-tailed $a$ of $0.05,92$ women would be needed in each arm. Assuming a $7.5 \%$ fall-out rate from women with nonviable pregnancies, 100 patients were required in each arm for a total enrollment of 200 women.

Following completion of the pilot study, the standard deviation for the knowledge questionnaire in the pilot population was noted to be 2.2 questions. The power calculation was repeated with the same parameters otherwise noted above, and 61 women would be required in each arm to show noninferiority for a total of 122 women. We chose to initiate the study with our initial power calculation to ensure we would maintain adequate power for our primary outcome; the pilot study sample was not used in the final cohort analysis.

Secondary outcomes included decisional conflict following decision aid completion, decisional conflict following decision aid completion and genetic counseling, change in knowledge score after genetic counseling in women who used the decision aid, choice of testing, and pursuit of invasive testing with high risk results. All women in group 2 were also asked whether they found it helpful to meet with a genetic counselor in addition to completing the decision aid. Two months after the initiation of enrollment, genetic counselors began routinely counseling all patients on options for carrier screening in addition to aneuploidy screening; at that time, the decision was made to both describe the answer to this question in all patients and to evaluate whether women were more likely to answer yes to this question after this change.
Additionally, exploratory subgroup analyses were planned to examine the performance of the decision group in women with low educational attainment (did not graduate high school) and in Spanish-speaking women.

All analysis was by intent to treat. Chi square, Fisher's exact, Wilcoxon rank-sum, and Wilcoxon signed-rank tests were used as appropriate. All analysis was done with STATA version 14.0 (College Station, TX).

This study was institutional review board (IRB) approved prior to initiation (UNC IRB \#15-1745), and was registered with ClinicalTrials.gov prior to study initiation (NCT02991729).

\section{RESULTS}

Between January and October 2017, a total of 1308 women with scheduled genetic counseling appointments were screened for eligibility (Fig. 1). Of these, 640 women were eligible; 365 eligible women were able to be contacted, and of these, 102 declined. Eligible women who participated and those who did not participate were similar in race/ethnicity and insurance status (Table S1). Of the 263 women who agreed to participate, 197 arrived prior to their appointment to participate and were enrolled and randomized, representing a $54 \%$ participation rate of women able to be contacted. Of the participants, 105 women were assigned to group 1, and 92 to group 2. Baseline demographic characteristics were similar between groups (Table 1); the majority of participating women were white, privately insured, had at least a college education, and were in their first trimester. The proportion of women who had previously seen a genetic counselor was 
Table 1 Baseline population characteristics at study enrollment

\begin{tabular}{|c|c|c|c|}
\hline & $\begin{array}{l}\text { Routine counseling } \\
(n=105), n(\%)\end{array}$ & $\begin{array}{l}\text { Decision aid } \\
(n=92), n(\%)\end{array}$ & $\begin{array}{l}p \\
\text { value }\end{array}$ \\
\hline Mean age $(95 \% \mathrm{Cl})$ & $32.4(31.3,33.5)$ & $\begin{array}{l}32.7 \text { (31.6, } \\
33.9)\end{array}$ & 0.945 \\
\hline AMA (age >35) & $48(45.7 \%)$ & $37(40.2 \%)$ & 0.437 \\
\hline Race/ethnicity & & & 0.101 \\
\hline White & $63(60.0 \%)$ & $47(51.0 \%)$ & \\
\hline Black & $19(18.1 \%)$ & $10(10.9 \%)$ & \\
\hline Hispanic/Latino & $15(14.3 \%)$ & $24(26.1 \%)$ & \\
\hline Asian & $5(4.8 \%)$ & $9(9.8 \%)$ & \\
\hline Other & $3(2.9 \%)$ & $2(2.2 \%)$ & \\
\hline Spanish-speaking & $10(9.5 \%)$ & $14(15.2 \%)$ & 0.233 \\
\hline Parity & & & 0.637 \\
\hline 0 & $44(41.9 \%)$ & $36(39.1 \%)$ & \\
\hline 1 & $35(33.3 \%)$ & $36(39.1 \%)$ & \\
\hline $2-4$ & $24(22.9 \%)$ & $20(21.7 \%)$ & \\
\hline$\geq 5$ & $2(1.9 \%)$ & 0 & \\
\hline $\begin{array}{l}\text { Mean gestational } \\
\text { age }(95 \% \mathrm{Cl})\end{array}$ & $12.1(11.8,12.4)$ & $\begin{array}{l}12.3(11.9 \\
12.7)\end{array}$ & 0.520 \\
\hline Site of enrollment & & & 0.936 \\
\hline $\begin{array}{l}\text { Public } \\
\text { hospital-based clinic }\end{array}$ & $72(69.9 \%)$ & $62(71.3 \%)$ & \\
\hline $\begin{array}{l}\text { Private } \\
\text { hospital-based clinic }\end{array}$ & $30(29.1 \%)$ & $24(27.6 \%)$ & \\
\hline Offsite clinic & $1(1.0 \%)$ & $1(1.1 \%)$ & \\
\hline Insurance status & & & 0.514 \\
\hline Medicare & 0 & $3(3.3 \%)$ & \\
\hline Medicaid & $18(17.1 \%)$ & $17(18.5 \%)$ & \\
\hline Privately insured & $68(64.8 \%)$ & $56(60.9 \%)$ & \\
\hline Tricare & $3(2.9 \%)$ & $2(2.2 \%)$ & \\
\hline Uninsured & $16(15.2 \%)$ & $14(15.2 \%)$ & \\
\hline Employed & 75 (71.4\%) & $58(63.0 \%)$ & 0.357 \\
\hline Education level & & & 0.051 \\
\hline $\begin{array}{l}\text { Middle school or } \\
\text { less }\end{array}$ & $3(2.9 \%)$ & $7(7.6 \%)$ & \\
\hline Some high school & $6(5.7 \%)$ & 0 & \\
\hline $\begin{array}{l}\text { Completed high } \\
\text { school }\end{array}$ & $25(23.8 \%)$ & $23(25.0 \%)$ & \\
\hline College graduate & $36(34.3 \%)$ & $37(40.2 \%)$ & \\
\hline Graduate degree & $33(31.4 \%)$ & $21(22.8 \%)$ & \\
\hline $\begin{array}{l}\text { Genetic counseling } \\
\text { in a prior pregnancy }\end{array}$ & $31(29.5 \%)$ & $33(35.9 \%)$ & 0.280 \\
\hline $\begin{array}{l}\text { Planning invasive } \\
\text { testing }\end{array}$ & $1(1.0 \%)$ & $3(3.3 \%)$ & 0.341 \\
\hline $\begin{array}{l}\text { Mean knowledge } \\
\text { score (SD) }\end{array}$ & $10.0(2.3)$ & $9.9(2.5)$ & 0.774 \\
\hline
\end{tabular}

$A M A$ advanced maternal age, $\mathrm{Cl}$ confidence interval

similar between groups. Baseline knowledge scores were similar between groups (10.0 in group 1 and 9.9 in group 2 on a 12 -point scale, $p=0.774$ ).
Table 2 Outcomes following counseling modality

\begin{tabular}{|c|c|c|c|}
\hline & $\begin{array}{l}\text { Group } 1 \text { following } \\
\text { genetic counseling } \\
(n=105)\end{array}$ & $\begin{array}{l}\text { Group } 2 \\
\text { following decision } \\
\text { aid use }(n=92)\end{array}$ & $\begin{array}{l}p \\
\text { value }\end{array}$ \\
\hline $\begin{array}{l}\text { Knowledge } \\
\text { score (mean, } \\
\text { SD) }\end{array}$ & $10.6(1.9)$ & $10.4(2.4)$ & 0.929 \\
\hline $\begin{array}{l}\text { Decisional } \\
\text { conflict score } \\
\text { (mean, SD) }\end{array}$ & $1.7(4.8)$ & $1.6(0.9,2.4)$ & 0.369 \\
\hline $\begin{array}{l}\text { Planned test, } n \\
(\%)\end{array}$ & $(n=96)$ & $(n=85)$ & 0.360 \\
\hline $\begin{array}{l}\text { None/ } \\
\text { ultrasound } \\
\text { only }\end{array}$ & $19(19.8 \%)$ & $17(20.0 \%)$ & \\
\hline $\begin{array}{l}\text { First trimester } \\
\text { screen }\end{array}$ & $36(37.5 \%)$ & $35(41.2 \%)$ & \\
\hline Cell-free DNA & $39(40.6 \%)$ & $27(31.8 \%)$ & \\
\hline $\begin{array}{l}\text { Quadruple } \\
\text { analyte screen }\end{array}$ & 0 & $3(3.5 \%)$ & \\
\hline $\begin{array}{l}\text { Chorionic } \\
\text { villus sampling }\end{array}$ & 0 & 0 & \\
\hline Amniocentesis & 0 & $1(1.2 \%)$ & \\
\hline Don't know & $2(2.1 \%)$ & $2(2.4 \%)$ & \\
\hline
\end{tabular}

The decision aid took women an average of $21 \mathrm{~min}$ to complete. Primary and secondary outcome measures following decision aid completion are seen in Table 2; primary and secondary outcome measures following both decision aid and genetic counseling completion are seen in Table 3 . Knowledge score following completion of the decision aid in group 2 was not inferior to knowledge score following genetic counseling in group 1 ( 10.4 vs. 10.6, $p=0.929$; Figure S2). Knowledge following both the decision aid and genetic counseling was not superior to knowledge following genetic counseling alone (10.9 vs. $10.6, p=0.306)$, and was also not superior to knowledge following decision aid completion alone (10.9 vs. $10.4, p=0.541)$.

Decisional conflict score following completion of the decision aid in group 2 was similar to decisional conflict score following genetic counseling in group 1 (1.6 vs. 1.7, $p=$ 0.369 ), seen in Figure S3. Decisional conflict following both the decision aid and genetic counseling was lower than decisional conflict following genetic counseling alone ( 0.2 vs. $1.7, p=0.003)$, and was also lower than decisional conflict following decision aid completion alone (0.2 vs. 1.6, $p=$ 0.003 ). Of women in group $2,67.5 \%$ of women stated they would find it helpful to meet with a genetic counselor following completion of the decision aid, and $88 \%$ of women stated that they found genetic counseling to be helpful in addition to the decision aid after they completed their appointment. This did not differ in those who did and did not receive a discussion of carrier screening; all women in group 2 who were enrolled prior to the standardized addition of 
Table 3 Secondary outcomes following both decision aid use and genetic counseling
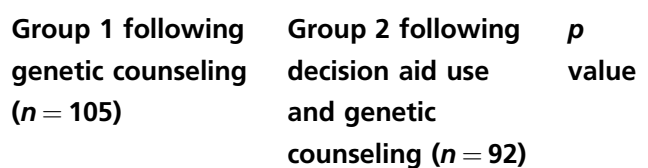

\begin{tabular}{|c|c|c|c|}
\hline $\begin{array}{l}\text { Knowledge } \\
\text { score (mean, } \\
\text { SD) }\end{array}$ & $10.6(1.9)$ & $10.9(1.6)$ & 0.306 \\
\hline $\begin{array}{l}\text { Decisional } \\
\text { conflict score } \\
\text { (mean, SD) }\end{array}$ & $1.7(4.8)$ & $0.2(3.5)$ & 0.003 \\
\hline $\begin{array}{l}\text { Planned test, } n \\
(\%)\end{array}$ & $(n=96)$ & $(n=67)$ & 0.327 \\
\hline $\begin{array}{l}\text { None/ } \\
\text { ultrasound } \\
\text { only }\end{array}$ & 19 (19.8\%) & $11(16.4 \%)$ & \\
\hline $\begin{array}{l}\text { First trimester } \\
\text { screen }\end{array}$ & $36(37.5 \%)$ & $28(41.8 \%)$ & \\
\hline Cell-free DNA & $39(40.6 \%)$ & $25(37.3 \%)$ & \\
\hline $\begin{array}{l}\text { Quadruple } \\
\text { analyte screen }\end{array}$ & 0 & $2(3.0 \%)$ & \\
\hline $\begin{array}{l}\text { Chorionic } \\
\text { villus sampling }\end{array}$ & 0 & $1(1.5 \%)$ & \\
\hline Amniocentesis & 0 & 0 & \\
\hline Don't know & $2(2.1 \%)$ & 0 & \\
\hline
\end{tabular}

carrier screening counseling stated that they found genetic counseling helpful.

A post hoc power analysis was performed to assess for noninferiority of decisional conflict in women in group 2 who had completed the decision aid only as compared with women in group 1 following genetic counseling. Given the standard deviation of 3.88 points in our study population and assuming a noninferiority limit of 1 point on the decisional conflict scale and an $\alpha$ of 0.05 , we had $86 \%$ power to detect noninferiority of this outcome.

As seen in Table 2, choice of test also did not differ between groups. Very few women opted for diagnostic testing. Overall, 16 of 92 women in group $2(17.4 \%)$ changed their planned test after genetic counseling. Most of these changes were changes between screening tests; three women who had initially planned no screening chose to undergo screening following genetic counseling, one woman who had initially planned amniocentesis ultimately chose screening, and one woman who had initially planned no screening chose to undergo chorionic villus sampling following genetic counseling. A total of six women, four in group 1 and two in group 2, had high risk results from screening, and of these, 50\% (two in group 1 and one in group 2), ultimately opted for invasive testing.

Prespecified exploratory analyses were performed for Spanish-speaking women and women with less than a high school education; these were underpowered and intended to be hypothesis-generating. Twenty-four women were Spanishspeaking; 10 of these women were randomized to group 1 and 14 to group 2. Knowledge scores at enrollment were similar between groups (5.7 in group 1 and 6.7 in group 2). Knowledge scores following genetic counseling in group 1 were similar to knowledge scores following decision aid use in group 2 (7.0 and 7.8, respectively). Knowledge scores following genetic counseling in group 1 were also similar to knowledge scores following both decision aid use and genetic counseling in group 2 (7.0 and 9.3, respectively). Women in the Spanish-speaking group answered on average 1.2 more questions correctly compared with 0.3 more questions answered correctly in the English-speaking group $(p=0.114)$.

Sixteen women had less than a high school education; 9 of these women were randomized to group 1 and 7 to group 2 . All of these women who were randomized to group 2 had a less than 8th grade education. Women with less than a high school education had similar mean knowledge scores at enrollment (7.4 in group 1 and. 5.2 in group 2). Knowledge scores following genetic counseling in group 1 were similar to knowledge scores following decision aid use in group 2 (8.1 and 6.3 , respectively). Knowledge scores following genetic counseling in group 1 were also similar to knowledge scores following both decision aid use and genetic counseling in group 2 (8.1 and 9.5, respectively). After use of the decision aid, women in group 2 with less than a high school education answered on average 1.17 more questions correctly compared with 0.37 questions in women with greater than a high school education $(p=0.382)$.

\section{DISCUSSION}

Knowledge scores in women who use a decision aid for aneuploidy screening are not inferior to those of women who meet with a genetic counselor. The addition of genetic counseling to decision aid use reduced decisional conflict but did not significantly increase knowledge. Previous studies have assessed the impact of decision aids on aneuploidy screening decisions. A large randomized controlled trial by Kuppermann et al. demonstrated improved knowledge scores and less decisional uncertainty among women who used a computerized decision aid compared with women who received an educational booklet that is given to all women in their population during prenatal care. ${ }^{8}$ These women did not receive genetic counseling. Additionally, this tool was developed before the availability of cell-free DNA and so does not incorporate this option.

Similar to the authors of the aforementioned study, we also chose to use knowledge as a primary outcome, both to be consistent with existing literature and to ensure that women who may in the future use the decision aid in the absence of genetic counseling would be making a similarly informed decision about their care to those who receive genetic counseling, which is our current standard of care given the detail of counseling recommended by the ACMG for women who are considering cell-free DNA for 
aneuploidy screening. ${ }^{5}$ However, arguably equally important is the concept of decisional conflict and that women feel appropriately supported and confident in their decision, regardless of knowledge. In our study population, women who had only completed the decision aid had similar decisional conflict to those who saw the genetic counselor only, but decisional conflict was significantly reduced in those who were exposed to both modalities. Additionally, those who used the tool still felt it was helpful to meet with a genetic counselor, underscoring the utility of counseling via multiple modalities to support a fully educated patient choice.

Exploratory analyses of Spanish-speaking women and women with lower educational attainment demonstrated potential for improved knowledge after using both the decision aid and genetic counseling, although we were not adequately powered to demonstrate this. This warrants further study.

Interestingly, many women in group $2(17.4 \%)$ reported a different choice of test following genetic counseling than they reported following decision aid use. While this may have occurred due to increased knowledge gained during counseling, causing women to change their mind about their chosen test, it is also possible that women also have difficulty identifying the name of tests they would prefer to choose. It has been previously established that many women $(12 \%$ in a prior study) ${ }^{12}$ incorrectly identify which screening test they had done, which is understandable given the complexity of choices.

The strengths of our study include its randomized nature. As such, baseline groups were similar. Data entry was completed and then double-checked to ensure accuracy. Both English and Spanish-speaking women were included. Knowledge and decisional conflict were assessed with validated, low literacy tools, though the knowledge questionnaire was modified to include more updated screening modalities. We were adequately powered for a noninferiority outcome for knowledge, and post hoc power analysis demonstrates noninferiority for decisional conflict as well. Genetic counselors were asked prior to study initiation not to alter counseling based on randomization assignment. Additionally, all randomized women participated in the study and there was no loss to follow-up.

We must acknowledge limitations of the study. Blinding was not performed as it was not pragmatic for this study; many women were eager to discuss the decision aid with the genetic counselor when it was used. We were not powered to detect noninferiority for decisional conflict among women who had only used the decision aid as compared with women who had only seen the genetic counselor. Additionally, while we aimed to recruit a more diverse population, the majority of our patients were white and highly educated, with higher baseline knowledge scores than anticipated. This may have occurred because these women may have been more easily contacted prior to their genetic counseling appointment, and may have had more resources to be able to present early to their appointment for study enrollment. These demographic findings do limit our generalizability.

Given known disparities in knowledge and prenatal counseling for women in low-income settings and for women for whom English is not their primary language, decision aids have great potential for reaching these underserved groups in a standardized and accessible way. While we were not powered to evaluate our decision aid in Spanish-speaking women or women with low educational attainment, exploratory analyses show promise in improving knowledge and decisional conflict in these groups. Larger studies targeted at these populations are needed to evaluate decision aids in these women, because decision aids could help reduce disparities in prenatal counseling.

While we are fortunate at our center to have access to genetic counselors who see many patients planning aneuploidy screening, the vast majority of the prenatal care providers are not so fortunate. At the least, our decision aid is not inferior to genetic counseling in patient knowledge and decisional conflict and can be considered for use in populations such as the one studied here. In populations with access to a genetic counselor, the decision aid adds utility in reducing decisional conflict and its use should be considered. Future studies validating use in populations with lower educational attainment and in Spanish-speaking populations are planned.

\section{ELECTRONIC SUPPLEMENTARY MATERIAL}

The online version of this article (https://doi.org/10.1038/s41436018-0283-2) contains supplementary material, which is available to authorized users.

\section{ACKNOWLEDGEMENTS}

The authors would like to thank Karen Dorman, Zoe Froelking, Amber Ivins, Laarni Lapat, Olivia Barnes, Norma Hernandez, and Catherine Vladutiu. The project described was supported by the Clinical and Translational Science Award program of the Division of Research Resources, National Institutes of Health, through grant award no. 1UL1TR001111, by the UNC Center for Maternal and Infant Health, through the Cefalo-Bowes Young Researcher Award, and by the Eunice Kennedy Shriver National Institute of Child Health and Human Development BIRCWH K12 Grant HD001441 (N.L.V.) and K23 HD088742 (N.L.V.). This study was registered at clinicaltrials.gov prior to enrollment (NCT02991729); https://clinicaltrials.gov/ct2/show/NCT02991729.

\section{DISCLOSURE}

The authors declare no conflicts of interest.

\section{REFERENCES}

1. Gil MM, Accurti V, Santacruz B, Plana MN, Nicolaides KH. Analysis of cellfree DNA in maternal blood in screening for aneuploidies: updated metaanalysis. Ultrasound Obstet Gynecol. 2017;50:302-314.

2. Norton ME, Baer RJ, Wapner RJ, Kuppermann M, Jelliffe-Pawlowski LL, Currier RJ. Cell-free DNA vs sequential screening for the detection of fetal chromosomal abnormalities. Am J Obstet Gynecol. 2016;214:727 e721-726. 
3. Akolekar R, Beta J, Picciarelli G, Ogilvie C, D'Antonio F. Procedure-related risk of miscarriage following amniocentesis and chorionic villus sampling: a systematic review and meta-analysis. Ultrasound Obstet Gynecol. 2015;45:16-26

4. Practice Bulletin No. 163: Screening for fetal aneuploidy. Obstet Gynecol. 2016;127:e123-137.

5. Gregg AR, Gross SJ, Best RG, et al. ACMG statement on noninvasive prenatal screening for fetal aneuploidy. Genet Med. 2013;15:395-398.

6. Stacey D, Legare F, Col NF, et al. Decision aids for people facing health treatment or screening decisions. Cochrane Database Syst Rev. 2014;1: CD001431.

7. Dugas M, Shorten A, Dube E, Wassef M, Bujold E, Chaillet N. Decision aid tools to support women's decision making in pregnancy and birth: a systematic review and meta-analysis. Soc Sci Med. 2012;74:1968-1978.
8. Kuppermann M, Norton ME, Gates $\mathrm{E}$, et al. Computerized prenatal genetic testing decision-assisting tool: a randomized controlled trial. Obstet Gynecol. 2009;113:53-63.

9. Goel V, Glazier R, Holzapfel S, Pugh P, Summers A. Evaluating patient's knowledge of maternal serum screening. Prenat Diagn. 1996;16:425-430.

10. Linder SK, Swank PR, Vernon SW, Mullen PD, Morgan RO, Volk RJ. Validity of a low literacy version of the Decisional Conflict Scale. Patient Educ Couns. 2011;85:521-524.

11. Harris PA, Taylor R, Thielke R, Payne J, Gonzalez N, Conde JG. Research electronic data capture (REDCap) - a metadata-driven methodology and workflow process for providing translational research informatics support. J Biomed Inform. 2009;42:377-381.

12. Bryant $A S$, Norton ME, Nakagawa $S$, et al. Variation in women's understanding of prenatal testing. Obstet Gynecol. 2015;125:1306-1312. 